\title{
Common Virtue and the Perspectival Imagination: Adam Smith and Common Law Reasoning
}

\author{
Maksymilian Del Mar
}

\section{Introduction}

One of the fundamental differences in theoretical orientation and temperament is one's stance on everyday life: for instance, as a moral philosopher, does one believe in and take faith in the richness and resourcefulness of ordinary life and the achievable virtues of ordinary people, or does one, instead, pursue the utopian construction of excellence - that mysterious, necessarily elite, wisdom of the sages? One can see the same issue in other areas of philosophy - in the philosophy of language, for example, one sees some philosophers eager to get dirty (and trying hard to remain) in the rough ground of ordinary use, and others with white gloves, busy in some distant corner, constructing the perfect and impossibly elegant language.

In the name of the virtue of candour, let me say immediately that my orientation and temperament is for the former: for the rough ground and the resourcefulness of ordinary life. It is perhaps that orientation and temperament that leads me to keep returning to the common law tradition. For all the complaints about the common law and there have been many: one need only think of the work of Jeremy Bentham - there is, surely, one hallmark of that tradition which is undeniable and, I would argue, deserves admiration, namely its unrelenting defence of common virtue. One of the vehicles for that defence- is the construction of perspectival devices - or so I argue in this paper. Some of these are very familiar: the reasonable person or the person of ordinary prudence. Others are less so, such as the 'the right-thinking member of society' in defamation law, or 'the reasonably well-informed and normally-diligent tenderer'. All of these are, arguably, devices of common virtue: they incorporate and protect ordinary rather than extraordinary interactional expectancies, and are based in relatively localised and historically situated social practices.

The history of moral philosophy - including the history of virtue ethics - has seen its fair share of utopian, ideal, demanding, and extraordinary constructions. But there have also been some steadfast defenders of the moral resourcefulness of common virtue. One of the figures that stands out in this respect is Adam Smith, whose Theory of Moral Sentiments ${ }^{1}$ (hereinafter 'TMS') constitutes one of the most powerful, most lyrical paeans to common virtue ever written. ${ }^{2}$ It, too, alongside the practices of common law reasoning, is a work I find myself returning to often.

In this paper, I propose comparing Adam Smith's construction of a spectator and the role it plays in his moral theory with the use of perspectival devices in the common law. Applying Smith to the practice of legal judgement is, of course, anything but original. ${ }^{3}$ As helpful and instructive as these other applications are, however, none

\footnotetext{
${ }^{1}$ Adam Smith. The Theory of Moral Sentiments (Cambridge University Press, 2002 [1790]).

${ }^{2}$ Other philosophers one can include as such defenders include Iris Murdoch (The Sovereignty of Good (Routledge, 1970)), Susan Wolf ('Moral Saints' (1982) 79 The Journal of Philosophy 419), Bernard Williams (Ethics and the Limits of Philosophy (Fontana Press, 1985)), and Cora Diamond (The Realistic Spirit (MIT Press, 1991)).

${ }^{3}$ See, eg Neil MacCormick's attempt in his last book, Practical Reason in Law and Morality (Oxford University Press, 2008). But see also Luigi Bagolini. 'The Topicality of Adam Smith's Notion of Sympathy and Judicial Evaluations' in Andrew Skinner and Thomas Wilson (eds), Essays on Adam
} 
known to me have engaged in any detail with how perspectival devices are used in the common law. This may be in part because not everyone accepts the interpretation of Smith I embrace here, namely an interpretation that emphasises the exercise of imaginative sympathy by an ordinarily virtuous, and culturally and historically situated, spectator, with a particular focus on the quality of that spectator's description of the situation at hand.

There are two parts to the paper. In the first, I offer an interpretation of Smith, focusing on two questions: first, who is the spectator, and second, what does the spectator do? In the second part, I turn to the use of perspectival devices in the common law, first giving a brief overview of the variety of such devices, and then going on to focus on the use of the 'right-thinking member of society' device in the famous case of Sim $v$ Stretch. ${ }^{4}$

\section{Common Virtue and the Perspectival Imagination}

The two dimensions of Smith's TMS I wish to emphasise are found already in its first two opening paragraphs. In the first, Smith introduces the overall tenor of his approach - namely, that he will be endeavouring to identify a foundation for generating standards that is achievable for all, ie the capacity for fellow-feeling is inclusive of even 'the greatest ruffian, the most hardened violator of the laws of society'. ${ }^{5}$ In the second, Smith notes that the capacity of fellow-feeling is dependent on the imagination - we do not have 'immediate experience of what other men feel', and so we need to draw on the imagination to 'carry us beyond our own person'- and here already Smith links the imagination to a description of the 'situation' in which the other (the agent being observed) finds himself or herself. ${ }^{6}$

In two sections below, I will expand on both of these dimensions by answering two questions: first, who is the spectator? And second, what does the spectator do? In brief, I will adopt the view of those commentators who argue that Smith's spectator is by no means an ideal observer, as some have characterised him, ${ }^{7}$ but rather the embodiment of an average and ordinary observer, and one furthermore located in a particular community, with its own customs and its own history. This average and ordinary observer does possess certain virtues - eg he is impartial in the sense that his personal interests are not at stake in the situation being observed; he is aware of the community's customs and traditions; and he is attune to the feelings of those in the situation - but these are hardly virtues of excellence or virtues that only a select few can obtain, even though their exercise certainly requires effort. Having the construction of the perspective at hand - one of common virtue - the next task is to articulate what the observer does. Here, I will focus on what Smith meant by 'imaginative sympathy', and in particular, his focus on the quality of description of the situation. Having articulated the basics of Smith's spectator in this way, we will then be well-braced for comparing it with the construction of perspectives in common law reasoning.

Smith (Clarendon Press, 1975) 100-113. See also the references therein to Italian literature on Smith and legal reasoning.

${ }^{4}$ Sim v Stretch [1936] 2 All ER 1237.

${ }^{5}$ See Smith (n 1) I.I.1.

6 ibid, I.I.2

${ }^{7}$ For the purposes of this paper, I refer to the spectator as a 'he', as this is consistent with Smith's usage and with commentators after him. In doing so, I by no means wish to underestimate the importance of a feminist critique of the gendering of not only the Smithian spectator, but also other perspectival devices (including in the common law). I reserve this topic, however, for another occasion. 


\section{I.A. Who is the Spectator?}

There have been a number of important defences of the ordinariness of Smith's spectator, but two stand out: Tom Campbell's interpretation in his Adam Smith's Science of Morals, ${ }^{8}$ and Charles Griswold's more recent Adam Smith and the Virtues of Enlightenment. ${ }^{9}$

Campbell's critical target is a well-known paper by Roderick Firth, 'Ethical Absolutism and the Ideal Observer'. ${ }^{10}$ In that paper, Firth argued for an 'ideal observer' analysis of the Smithian spectator, with attributes such as: omniscience with respect to all non-ethical facts; omnipercipience (that is, the ability to "visualise all actual facts, and the consequences of all possible acts in any given situation, just as vividly as he would if he were actually perceiving them all'); ${ }^{11}$ and dispassion, meaning that as an impartial judge, the ideal observer would be 'unaffected ... by his emotions'. ${ }^{12}$

Campbell argues powerfully against this view. The one sense in which the Smithian spectator is 'ideal', he said, was that 'he excludes all those features of actual spectators which relate to their special interests as particular individuals involved in the actual situation which they are observing'. ${ }^{13}$ In other words, the spectator is 'ideal', and equally 'impartial', 'indifferent' and 'disinterested', only in the sense that he does not have something personal at stake in the situation he is observing. The Smithian spectator is certainly not 'dispassionate', ie, he is not 'indifferent' in the sense that he is without emotion. To the contrary, he has 'all the normal feelings characteristic of human nature', eg 'he has the same desires to obtain pleasure and avoid pain'. ${ }^{14}$ Very significantly, this includes being subject to the same 'laws of emotion' that average human beings are subject to, ie 'all the failings and irregularities which alter the usual operations of the moral sentiments'. ${ }^{15}$ For example:

He feels the 'irregularity' of sentiments due to the influence of fortune, and enters into the 'fallacious sense of guilt' associated with such cases. He too is 'blinded by success' and shares in the admiration of the mass of mankind for wealth and greatness. ${ }^{16}$

The spectator thus "embodies the principles by which a "weak and imperfect being" actually does approve and disapprove of actions" ${ }^{17}$ - he is, if you like, chock-full of

\footnotetext{
${ }^{8}$ Tom Campbell, Adam Smith's Science of Morals (George Allen \& Unwin, 1971).

${ }^{9}$ Charles Griswold, Adam Smith and the Virtues of Enlightenment (Cambridge University Press, 1999).

These interpretations are largely endorsed by other influential commentators. See, David Raphael, The Impartial Spectator: Adam Smith's Moral Philosophy (Oxford University Press, 2007).

10 Roderick Firth, 'Ethical Absolutism and the Ideal Observer' (1952) 12 Philosophy and Phenomenological Research 317.

11 ibid, 335.

12 ibid, 340.

${ }^{13}$ See, Campbell (n 8) 127.

14 ibid, 136.

15 ibid.

16 ibid.

17 ibid, 137.
} 
average humanity. As Campbell does not tire of emphasising, 'the spectator represents, in the first instance, the average or normal or ordinary man'. ${ }^{18}$

Of course, the Smithian spectator does have certain attributes, even virtues, but these are very much virtues in moderation. Because he is not personally invested in the stakes of the drama, the spectator is not as affected - not as excited - by the emotions elicited by the situation as the agent being observed is likely to be. Nevertheless, he is certainly attuned to the feelings of those in the situation, and moreover, he does himself experience those feelings (in a lesser degree) or similar feelings, as a result of the imaginative effort of sympathising with the agent. Furthermore, the spectator is wellinformed - 'he knows the facts of the case and he does not make judgements in matters of which he has inadequate knowledge' - but he is certainly not omniscient. ${ }^{19}$ And the spectator is visually attentive, but again, most definitely not omnipercipient. ${ }^{20}$ The impartial spectator, then, is moderately affectively sensitive, reasonably well-informed, and moderately visually attentive - all arguably virtues, but all also arguably achievable ones.

Also very significantly - and in a way that contributes to the commonality and ordinariness of the Smithian construction - the spectator is 'the product of a particular society' ${ }^{21}$ As Campbell puts it in another way, the spectator is 'an empirical concept, referring to the development of moral consensus in a society'. ${ }^{22}$ Thus, through 'his training and experience', the spectator 'has come to regard as normal the behaviour which is, or, in some cases, which was, suited to the circumstances... of that society'. ${ }^{23}$ This means that the spectator can take on a variety of guises, depending on the society or group (this decision of scope can be made in the course of constructing the perspective) in question. Thus, the spectator is the embodiment of common virtue, and the standards generated (because approved of) by the spectator in making his evaluations are also common virtues. Morality for Smith, says Campbell, is 'a social phenomenon, originating in and being sustained by [culturally and historically situated] social interaction', ${ }^{24}$ all of which is 'far removed from the abstract speculations of the Ideal Observer theory'. ${ }^{25}$

Charles Griswold's more recent interpretation of Smith supports this reading. Smith, says, Griswold, 'offers us a striking and sustained redemption of ordinary, prephilosophical human life' ${ }^{26}$ Throughout, the emphasis is on imperfection. ${ }^{27}$ Indeed, argues Griswold, 'reconciliation with imperfection is a key aim of Smith's thought'. ${ }^{28}$ As Griswold summarises it:

Smith articulates and defends a notion of 'middling' moral virtue ... This more achievable notion of virtue is taken as reconciled with the pursuit of such fundamental goods as health, pleasure, 'bettering our condition', high reputation and 'worldly goods'. It is available to nearly every decent adult and is more democratic and egalitarian than the ancient ideal... it grants ordinary people

\footnotetext{
18 ibid, 134.

19 ibid, 136.

20 ibid.

21 ibid, 144.

22 ibid, 139.

23 ibid, 144.

24 ibid, 167.

25 ibid, 145.

${ }^{26}$ See, Griswold (n 9) 15.

27 ibid, 13.

28 ibid, 21.
} 
their place in the sun. Smith is a devoted and resourceful defender of the standpoint of ordinary life..$^{29}$

Again, significantly for present purposes, this means that Smith 'never requires the impartial spectator to stop caring about the sentiments and thus about local and particular attachments'. ${ }^{30}$ The Smithian spectator is 'woven into the world - into practices, traditions, and institutions, for example' and, because of that, his evaluation will often begin (but not necessarily end) with 'established rules and standards' ${ }^{31}$ There are, of course, refinements in the spectator's perspective - as above, the spectator cares, is interested in the plight of his fellows, and is reasonably informed, knowledgeable, and visually and affectively attuned - but that is no more than a refinement: it is something that almost all human beings can exercise, though not without some effort.

\section{I.B. What does the Spectator do?}

We have, then, a picture of who the Smithian spectator is. What does he do? Here again I will have occasion to draw on the interpretations of Campbell and Griswold, but I would like to begin with an extraordinary passage from early on in the $T M S$ - the passage is lengthy, but its length is important for present purposes:

We sympathize even with the dead, and overlooking what is of real importance in their situation, that awful futurity which awaits them, we are chiefly affected by those circumstances which strike our senses, but can have no influence upon their happiness. It is miserable, we think, to be deprived of the light of the sun; to be shut out from life and conversation; to be laid in the cold grave a prey to corruption and the reptiles of the earth; to be no more thought of in this world, but to be obliterated in a little time from the affections and almost from the memory of their dearest friends and relations. Surely, we imagine, we can never feel too much for those who have suffered so dreadful a calamity. The tribute of our fellow-feeling seems doubly due to them now when they are in danger of being forgot by every body: and, by the vain honours which we pay to their memory, we endeavour, for our own misery, artificially to keep alive our melancholy remembrance of their misfortune. That our sympathy can afford them no consolation seems to be an addition to their calamity; and to think that all we can do is unavailing, and that, what alleviates all other distress, the regret, the love and the lamentation of their friends, can yield no comfort to them, serves only to exasperate our sense of their misery. The happiness of the dead, however, most assuredly, is affected by none of these circumstances; nor is it the thought of these things which can ever disturb the security of their repose. The idea of that dreary and endless melancholy, which the fancy naturally ascribes to their condition, arises altogether from our joining to the change which has been produced upon them, our own consciousness of that change, from our putting ourselves in their situation, and from our lodging, if I may be allowed to say so, our own living souls in their inanimated bodies, and thence conceiving what would be our emotions in this case. It is this very illusion of the imagination which renders the foresight of our own dissolution so terrible

\footnotetext{
29 ibid, 13.

30 ibid, 141 .

31 ibid, 146.
} 
to us, and the idea of those circumstances, which undoubtedly can give us no pain when we are dead, makes us miserable while we are alive. And from thence arises one of the most important principles in human nature, the dread of death, the great poison to the happiness, but the great restraint upon the injustice of mankind, which, while it afflicts and mortifies the individual, guards and protects the society. ${ }^{32}$

This passage will help bring out the key features of what the spectator does. The spectator carefully and patiently (hence the length) describes the situation - doing so because, through the imagination, he attempts to enter into how the situation is being experienced by the object of his sympathy. The description pays attention to the particulars, though these are particulars that the spectator must imagine - a task which is assisted and improved by taking a perspectival stance. One might say that there is a double construction of a perspective here: first, we construct the perspective of the spectator; and second, we describe the situation by having the spectator sympathise with the (possibly hypothetical) agent. In other words, the spectator (already a perspectival construction) enters into the perspective of the agent (which may sometimes be a hypothetical construction). There are, thus, three key ingredients in what the spectator does: there is the exercise of the imagination, which takes effort; there is the focus on the situation; and there is the carefully particularised description, achieved by the spectator sympathising with the experience of the agent. Let me briefly unpack this by reference to the interpretations of Campbell and Griswold.

One of the perennial debates surrounding Smith is just what he meant by 'sympathy'. Despite repeated protests, it is still common to see Smith's notion of sympathy being equated with empathy or emotional contagion. Such readings fail to recognise the vital role of imagination in Smith's account. As illustrated in the above excerpt, with the case of the spectator sympathising with the dead, Smith's notion hardly depends on the spectator feeling the same thing as the agent. Smith's spectator imaginatively changes places with the agent, but with the focus being on the spectator imaginatively entering the agent's situation, and seeing what feelings that brings about in the spectator. Campbell also points this out, referring to Smith's own early hint, that (quoting Smith) 'sympathy...does not arise so much from the view of the passion, as from that of the situation which excites it' ${ }^{33}$ Certainly, Smith does not rule out the possibility of direct sympathy (though even there, the spectator would necessarily experience the same feelings at a lower level of intensity) - but Smith's emphasis throughout is on 'imaginative sympathy' (as Campbell calls it). ${ }^{34}$ Through 'the work of the imagination' we use 'copies of our own sense impressions to build up a picture of what we should feel were we in another's place'. ${ }^{35}$ This is genuine work; it requires effort - it does not come naturally (though it is also eminently achievable by almost all human beings). For present purposes, what is important to see is that what the spectator does is use his imagination to reconstruct the agent's situation, paying attention to his own feelings in that situation and comparing them to the feelings the agent exhibits. If the feelings coincide, the spectator approves of the agent's conduct, and if they do not, then he does not approve of it. In that way, the spectator both makes a judgement, and generates standards of conduct. ${ }^{36}$

\footnotetext{
${ }^{32}$ See, Smith (n 1) I.I.13.

33 ibid, I.I.10. See, Campbell (n 8) 95.

${ }^{34}$ See, Campbell (n 8) 96.

35 ibid, 97.

${ }^{36}$ See, Raphael (n 9) 13-14.
} 
Griswold too stresses the role of the imagination: sympathy, for Smith, is 'an act of the imagination', and '[e]motions are themselves shaped by the imagination'. ${ }^{37}$ As Griswold interprets him, for Smith the fundamental role of imagination goes hand in hand with the careful, patient, particularistic description of the situation (which is also why so many of Smith's examples are literary). In order for us 'to understand and evaluate ethical situations ... our emotions should be engaged in the particulars of the context' in question. ${ }^{38}$ As Smith himself says:

It is only when particular examples are given that we perceive distinctly either the concord or disagreement between our own affections and those of the agent, or feel a social gratitude arise toward him in the one case, or a sympathetic resentment in the other. When we consider virtue and vice in an abstract and general manner, the qualities by which they excite these several sentiments seem in a great measure to disappear, and the sentiments themselves become less obvious and discernible. ${ }^{39}$

Moral philosophy, then, for Smith, is a 'descriptive' enterprise - at least as much as it is a constructive one. ${ }^{40}$ Moral judgement is not something that ordinarily is exercised, and also ought not to be exercised, from some 'synoptic and impersonal perspective' ${ }^{41}$ It is, rather, localised and 'grounded in sentiments', ${ }^{42}$ and it is 'guided by the subject matter, the particularities of the case, the story being recounted' ${ }^{43}$

I have, of course, barely scratched the surface of what the spectator does - I have not, for instance, delved into the dual evaluation by the spectator of the motive (the 'propriety') and the consequences (the 'merit') of the agent's conduct. We should, however, have enough of a picture of who the Smithian spectator is and what he does, to go on now and compare this construction with the uses of perspectival devices in the common law. ${ }^{44}$

\section{Perspectival Devices in the Common Law}

We have so far seen the Smithian moderately-virtuous, culturally and historically situated spectator at work, exercising his imaginative sympathy, and thus carefully and patiently describing the particularities - including the affectivity - of the situation at hand. Let us now turn to the use of perspectival devices in the common law, before finishing by comparing them to that Smithian spectator.

\footnotetext{
${ }^{37}$ See, Griswold (n 9) 15.

38 ibid, 60.

${ }^{39}$ See, Smith (n 1) IV.2.2.

${ }^{40}$ See, Griswold (n 9) 57.

41 ibid.

42 ibid.

43 ibid, 52. For the link with Murdoch, see Megan Laverty, Iris Murdoch's Ethics (Continuum, 2007), 19-29

${ }^{44}$ See, Bagolini (n 3) 103, who is also interested in 'what senses the sympathetic process, as outlined by Smith, is applicable to the decision of a judge'. He also emphasises the role of the imagination, concluding that 'The greater the participation of the judge in the various situations of the persons, even merely hypothetical, who directly or indirectly, totally or in part receive the effects of his decision, the more equitable the judge's decision may be said to be' (ibid, 112). Bagolini does not, however, consider the use of perspectival devices in the common law.
} 


\section{II.A. Varieties of Perspectival Devices}

Lord Reed opened his recent judgement in Healthcare at Home Ltd v Common Services Agency in the following way:

The Clapham omnibus has many passengers. The most venerable is the reasonable man, who was born during the reign of Victoria but remains in vigorous health. Amongst the other passengers are the right-thinking member of society, familiar from the law of defamation, the officious bystander, the reasonable parent, the reasonable landlord, and the fair-minded and informed observer, all of whom have had season tickets for many years. ${ }^{45}$

His Lordship went on to characterise this diverse and colourful bunch as belonging to 'an intellectual tradition of defining a legal standard by reference to a hypothetical person, which stretches back to the creation by Roman jurists of the figure of the bonus paterfamilias'. ${ }^{46}$ The hypothetically perspectival device utilised in that case was the 'reasonably well-informed and normally diligent tenderer' ${ }^{47}$ The characterisation of this perspective as 'hypothetical' was important in the reasoning of Lord Reed: the lower court had spent eight days hearing evidence, adduced by the appellant, from witnesses testifying 'to the effect that they had not understood the criteria in the same way as the successful tenderer' ${ }^{48}$ In dismissing the appeal, Lord Reed emphasised that any 'evidence as to what the tenderers themselves thought the criteria required is, essentially, irrelevant' (here endorsing Lord Justice Clerk's judgement from below). ${ }^{49}$ That is because, said Lord Reed, '[j]ust like those other juridical creations, such as the man on the Clapham omnibus (delict) or the officious bystander (contract), the court decides what that person would think by making its own evaluation against the background circumstances'. ${ }^{50}$ The issue is 'not what the invitation to tender meant, but whether its meaning would be clear to any reasonably well-informed and normally diligent tenderer'. ${ }^{51}$

These brief remarks on this recent case already allow for some observations about the use of perspectival devices in the common law. First, the perspective constructed is an artificial one - a hypothetical (hence the dismissal of evidence of what actual tenderers thought as irrelevant). Second, some of these perspectival devices are hypothetical reconstructions of actors (as in the case of the reasonably well-informed and normally diligent tenderer) and some are artificial constructions of observers (such as the officious bystander). Third, out of those which are constructions of observers, some may be of observers who interact with the actors in a hypothetical scenario (the officious bystander asks the parties a series of questions to determine whether it is likely that they would have intended a certain term to be included in the contract) and others

\footnotetext{
${ }^{45}$ Healthcare at Home Ltd v Common Services Agency [2014] SC (UKSC) 247, [1]

46 ibid, 2. I take this opportunity to add that I do not wish to make any claims in this paper as to either the uniqueness, or the relative frequency, of the use of perspectival devices in the common law, as compared to other legal traditions. I focus on the common law simply for the sake of space. Having said that, the usage of perspectival devices would make for an interesting subject for a comparative history across legal traditions.

47 ibid.

48 ibid, 18

49 ibid, 26

50 ibid, emphasis added.

51 ibid, 27, emphasis added.
} 
are of non-interactive observers (such as, arguably, at least some uses of the reasonable person as an agent who observes and evaluates the action after it has been performed or as it unfolds without interfering in any way). And fourth, whether or not an actor or an observer (and of whatever kind), the perspectival device can be given certain characteristics which will guide the kind of evaluation that is being made, eg the clarity of the tender's terms is being evaluated via someone 'reasonably well-informed' and 'normally diligent', not by someone with a $\mathrm{PhD}$ in linguistics or experienced in that line of business.

Given the sheer diversity of perspectival devices, it is unsurprising that their functions differ - even if they can all be thought, in broad terms, as enabling judgement and generating standards via the employment of a hypothetical perspective. These different functions include: first, determining whether to imply a term in a contract (exemplified by some devices such as the officious bystander). ${ }^{52}$ Second, helping to determine the meaning of an explicit term whether in a contract, tender or will (exemplified by devices such as the reasonably well-informed and normally diligent tenderer, and some more ad hoc devices) ${ }^{53}$ And third, evaluating the conduct of the defendant (such as the reasonable person in negligence) or, equally, the plaintiff's reaction to the defendant's action (as with the use of the reasonable person in discrimination cases to determine whether the action or statement was discriminatory). ${ }^{54}$

Why, one might ask, is the use of perspectival devices so frequent in common law reasoning? This is not the time for a comprehensive answer, but two proposals can be made: first, that, as Geoffrey Samuel ${ }^{55}$ has indicated, perspectival devices are ways of framing facts - or, as I prefer to think of it, they enable a richer (because more particular) description of the situation; second, because they are artificial constructions, they give the judges freedom to incorporate what they take to be standards of common sense and thereby defend what they take to be ordinary, reasonable interactional expectations, while at the same time enabling change (via the introduction of certain particular characteristics) to the context in question (eg adding 'diligence' as a character trait, or being 'well-informed', or being 'officious' etc.). The perspectival device, then, allows the judges to get close to the facts of the case (by adopting a perspective, they can describe the situation more richly), but not too close: by deciding what attributes the hypothetical person is to have, judges can regulate what they describe and how they evaluate it. Indeed, sometimes judges use a variety of possible perspectives (eg on some explicit term) as part of a process of deciding which is the most appropriate. In $R e$ Rowland, ${ }^{56}$ for example, in determining the meaning of 'coincide with' in a will, ${ }^{57}$ the judges refer to the interpretations of the term by an 'ordinary man', a 'metaphysician', and a 'grammarian'. Furthermore, not only is there flexibility in what attributes one includes, but there is flexibility as to how to interpret them - indeed, cases in areas of the law that deploy perspectival devices will often turn on what a particular character trait of the hypothetical person in question requires (eg what 'reasonableness' requires,

\footnotetext{
${ }^{52}$ The classic case here is Shirlaw $v$ Southern Foundries (1926) Ltd [1939] 2 KB 206, in particular Justice MacKinnon's judgement.

${ }^{53}$ Consider the use of perspectival devices in the interpretation of a will, in Re Rowland [1963] Ch 1 (CA).

${ }^{54}$ For an alternative classification, see Mayo Moran, 'The Reasonable Person: A Conceptual Biography in Comparative Perspective' (2010) 14 Lewis \& Clark Law Review 1233.

${ }^{55}$ Geoffrey Samuel, Epistemology and Method in Law (Ashgate, 2003).

${ }^{56}$ Re Rowland [1963] Ch 1 (CA).

${ }^{57}$ The issue was whether the deaths coincided or not, with different parties inheriting depending on whether they did.
} 
or 'attentiveness', or 'diligence', or 'prudence' etc.). ${ }^{58}$ Of course, what a sympathetic observer may characterise as 'flexibility', a cynic may characterise as an excuse for judicial arbitrariness - but I leave this discussion for another day.

In the section below, I focus on one example of a particular kind of perspectival device: the non-interfering observer, in character as 'a right-thinking member of society' in the context of defamation law. As we will see, even though this 'member' is a non-interfering observer, $\mathrm{s} / \mathrm{he}$ is still positioned in the particular context of the case, ie the device enables a certain view (and a certain normatively-loaded description) of the situation. The interesting point to make here is that the judges retain a certain amount of flexibility here too: how far they particularise the hypothetical person, eg which 'society' do they take for the purpose of constructing a 'right-thinking member' (the relatively small intimate group of friends, or the local community, or the nation, etc.). These are, as it were, decisions for the imagination to make - but in both cases, they are decisions made within the confines of a perspective that is very much a 'middling' one; the perspective of common, ordinary, average virtue (here: moderate sensitivity rather than excessive puritanism).

\section{II.B. 'The Right-Thinking Member of Society'}

It is hard to find a case as brief, entertaining, and instructive for present purposes as Sim v Stretch. ${ }^{59}$ The judgement by Lord Atkin (with whom the other two Lords concurred) is short: no more than five pages. Indeed, Lord Atkin is decidedly gruff that the case made it all the way up to the House of Lords: 'The truth of this case', he said, 'is that the whole matter is a trumpery affair' ${ }^{60}$ The affair, in short, concerned the employment of a domestic servant, Edith Saville. Originally employed by $\mathrm{Mr}$ and $\mathrm{Mrs}$ Sim of Cookham Dean (in a property entitled 'Old Barton'), Ms Saville entered into the employ of Mr and Mrs Stretch (also of Cookham Dean) upon their purchase of a property called 'The Twigs'. It appears that Mrs Sim was not happy about Ms Saville departing 'Old Barton' for 'The Twigs', and so at an opportune moment about a month later (when Mr and Mrs Stretch were out), Mr Sim went to the driveway at 'The Twigs' and called out for Ms Saville. Having captured her attention, Mr Sim then walked back with her to 'Old Barton', and together with Mrs Sim, the three of them drove to 'Georgian House' in Maidenhead (where Mr Sim's father lived). There it appears that Mr and Mrs Sim persuaded Ms Saville to leave the employ of Mr and Mrs Stretch, and re-join them, this time permanently. Having so persuaded Ms Saville, Mr Sim then went to the post office at Maidenhead and dictated the following telegram (which reached the post office - then housed in a village shop - in Cookham Dean): 'Stretch, The Twigs, Cookham Dean. Edith has resumed her service with us to-day. Please send her possessions and the money you borrowed also her wages to Old Barton. Sim. ${ }^{61}$ This must have come as a rude shock to Mr and Mrs Stretch - though it appears that the telegram was sent three days after Mr and Mrs Stretch would have returned to an empty house (having gone only to do some shopping and pay Ms Saville's wages for that month into the post office).

\footnotetext{
${ }^{58}$ See, for example, the Opinion of the Advocate-General and the Judgement of the Court in the PepsiCo case before the European Court of Justice, on how 'attentive' the 'informed user' in design law ought to be imagined to be. See, PepsiCo v Grupo Promer Mon Graphic SA [2011] CJEU Case C-281/10

${ }^{59}$ See, Sim v Stretch (n 4).

60 ibid, 1242.

61 ibid, 1238.
} 
$\mathrm{Mr}$ and Mrs Stretch sued Mr and Mrs Sim on two counts: for maliciously enticing the service of Ms Saville; and for the libel contained in the telegram. The lower courts, including the Court of Appeal, found in favour of Mr and Mrs Stretch. Mr and Mrs Sim did not appeal the finding on the malicious enticement, but they did appeal in the House of Lords - the libel. The damages were not insignificant: $£ 250$ for the libel (compared to the $£ 25$ for the malicious enticement). The appeal was successful: the House of Lords determined that the telegram did not contain words which, in their ordinary signification, were capable of any defamatory meaning. How did they so determine?

The case is significant because it is the first known instance of the Lords articulating (perhaps endorsing - for Lord Atkin said he had found the test after 'collating the opinions of many authorities' ${ }^{62}$ a then-new test of defamation: instead of the then-dominant test as to whether the phrase in question exposed the plaintiff to 'hatred, ridicule and contempt', which Lord Atkin said was 'probably too narrow', the proposed new test was: 'would the words tend to lower the plaintiff in the estimation of right-thinking members of society generally?'. ${ }^{63}$ This was a question of law - the court had to first decide whether the words used were capable of being defamatory in that sense, and only then would the matter go before a jury, which would decide whether the words were in fact defamatory. What is interesting for present purposes about this case is just how the 'right-thinking member of society' is constructed by Lord Atkin. We can thus ask two questions: who is this 'right-thinking member', and what do they do?

In searching for how to characterise this hypothetical person, Lord Atkin dismisses the possibility of it being the post office officials at Maidenhead - they surely would have no knowledge of the plaintiffs, and that is something that this hypothetical person must have (s/he must be reasonably well-informed). He thus locates the 'rightthinking member' in the village shop at Cookham Dean - indeed, his Lordship comes very close to identifying this hypothetical person with the person who received the telegram (and passed it on to the plaintiff). That is significant: it allows for a localised, particular description of the situation, and is in keeping with the interpretation of the Smithian impartial spectator above - namely, as a culturally and historically located observer. This is further demonstrated by the fact that his Lordship allows the rightthinking member to be aware of the usual practices surrounding the employment of a domestic servant - he attributes knowledge to the right-thinking member that it is 'a usual domestic occurrence for small sums to be advanced in such circumstances as the present'. ${ }^{64}$

Notice, then, that it is not a mere question of this right-thinking member being impartial - ie that they are not themselves invested in the drama. That is important, but in itself is not sufficient. What is needed is that this right-thinking member be informed by the knowledge of the community's practices. One might say, then, that the emotional sensitivity of this right-thinking member is tempered or softened by their knowledge of what is customary in the community. Someone who is more invested, such as the plaintiff, might ignore what is customary and read too much into the words used.

The other point to observe is that it is important that the right-thinking member embodies a link between emotion and those customary practices. The right-thinking member is not just aware of what the customary practices are - he or she is also aware of how they resonate emotionally, especially when something is done in breach of them.

\footnotetext{
62 ibid, 1240.

63 ibid.

${ }^{64}$ ibid, 1241.
} 
Thus, for example, Lord Atkin says that the right-thinking member might very well take the words to lower the plaintiff in their esteem if the amount was large or if it had been borrowed and 'left so long unpaid that the facts when known would reflect on the character of the master' ${ }^{65}$

The right-thinking member, then, is 1) impartial, in that $\mathrm{s}$ /he does not have something at stake personally in the situation; 2) is culturally and historically situated, and thus aware of the customary practices of the community; and 3) is emotionally attune, but not so sensitive as to read too much into the words used, but in a way that is guided by local knowledge of what is customary. Linking this to the conclusion reached by Lord Atkin, one might say that it is because the right-thinking member does not approve of the plaintiff's emotional reaction to the words used - their sentiment does not accord with that of the plaintiff - that Lord Atkin finds against the plaintiff.

By discussing the attributes of the right-thinking member, I have already delved into what it is that the right-thinking member does. That is as it should be, because it is in part by constructing the attributes of the perspective that a lot of the work of judgement (legal it seems, as much as moral) is done. Let me add a little more, though, by reference to how the perspective of the right-thinking member is described - ie to what this hypothetical person does.

When Lord Atkin first describes the reaction of the right-thinking member recall, the hypothetical person receiving the telegram at Cookham Dean - he says that they would learn the following by reading the telegram:

That Edith Saville had been in the plaintiff's employment; that she had that day entered into the defendant's employment; and that the former employer was requested to send on to the new place of employment the servant's possessions together with the money due to her for money borrowed and for wages. ${ }^{66}$

There are two different ways to read this construction. One is to say that Lord Atkin's reader reads first and foremost for information, and does not consider any emotional implications (unless perhaps pressed to consider if there are any). Another is to say that it is precisely the absence of any overt emotional reaction by the reader - the right-thinking member - that shows that the plaintiff's reaction is disproportionate and most likely based on his personal involvement in the drama.

In any event, Lord Atkin does press this hypothetical person to consider whether the words lower the plaintiff in their esteem - and, as already indicated above, based on the person's knowledge of the local customs, he asserts that it would not. Nevertheless, the right-thinking member is not entirely without emotion: as Lord Atkin goes on to say towards the end of his judgement, the words used may be taken to be 'exhibitions of bad manners or discourtesy', but that is not the same thing as an 'attack on character' ${ }^{67}$ The right-thinking member, then, would (1) primarily understand the words to be, pragmatically speaking, a fitting thing to do ${ }^{68}$. But (2) this hypothetical person is not without feeling, for they might very well consider the words (and perhaps the method, of a telegram) to be bad manners or display discourtesy, though they would

\footnotetext{
65 ibid.

66 ibid, 1240.

67 ibid, 1242.

68 'It was quite natural and proper that he [the defendant] should ask for the maid's possessions to be sent to a named address and natural that he should in the same communication ask that the money, which in fact was due to her, should be sent to the same place'. ibid, 1242.
} 
not go so far as to say that the words are an attack on the plaintiff's character and thus lower them in their esteem.

The right-thinking member's emotional reaction, then, is at odds with the plaintiff's reaction in this case: 'The truth of the case', to recall, 'is that the whole matter is a trumpery affair and...the alleged libel would probably never have been heard of but for the wounded feelings caused by the improper enticement' ${ }^{69}$ It is the plaintiff's personal investment in the drama - their having been robbed of a domestic servant that has led them to attach unwarranted implications and experience disproportionate feelings. As a result, the words used are not capable of defamatory meaning, and the appeal succeeds. ${ }^{70}$

\section{Conclusion}

We have now considered Smith's construction of the spectator, and also had occasion to explore an example of the use of a perspectival device in the common law: Lord Atkin's right-thinking member of society. In concluding, let me briefly compare them.

My tentative suggestion here is that there is indeed some correlation between the two. Lord Aktin's positioning of the right-thinking member as local, and thus informed of and emotionally attune to the customs and practices of the community of Cookham Dean, but at the same time not personally invested (so as to be too partial), allows him to offer a richer but also more balanced description of the situation than he might otherwise (eg if he simply had to determine whether, say, the words exposed the plaintiff to ridicule or hatred, or if he had taken the perspective of a member of English society in general and thus someone whose sentiments might not be tempered by knowledge of local customs).

The right-thinking member is a 'middling' device - the member is not excessively virtuous, but is rather common: not only in the sense of being local, but also in being reasonably well-informed and knowledgeable (but not omniscient: for instance, the member does not know of the entire history of quarrels between the two parties) and visually and emotionally attune (but not overly sensitive or omnipercipient). Nevertheless, Lord Atkin does have to exercise effort in constructing the perspective, and in describing the situation, including paying attention to the feelings the member might have and how they compare to the feelings claimed by the plaintiff.

These links, I suggest, bode well for future comparisons of Smith's device and other perspectival devices in the common law - and, more generally, for the pursuit, in moral as in legal philosophy, of the defence of the resourcefulness of common virtue, of ordinary life.

\footnotetext{
${ }^{69}$ ibid.

${ }^{70}$ For more on the subsequent use of this 'right-thinking member of society' test, see Hilary Young, 'But Names Won't Necessarily Hurt Me: Considering the Effect of Disparaging Statements on Reputation' (2011) 37 Queen's Law Journal 1.
} 